\title{
Fishing, trade, and local ecological knowledge of the marine gastropod, Cassis tuberosa - a target species of the international shell trade
}

\author{
Ellori Laíse Silva Mota ${ }^{1 *}$, Rômulo Romeu Nóbrega Alves ${ }^{2}$ and Thelma Lúcia Pereira Dias ${ }^{2}$
}

\begin{abstract}
Cassis tuberosa is one of the most exploited marine gastropods on the Brazilian coast, due to its aesthetic value. The lack of characterization of the species' trade makes it difficult to establish effective monitoring strategies. This is the first survey to characterize the fishing and trade chain of $C$. tuberosa, and to record aspects of local fishermen's traditional ecological knowledge of the species. C. tuberosa is caught while fishing for other target resources, such as fish, lobsters, and octopuses. The most popular use of the shell is for ornamental purposes, and the demand for this is enhanced by the intensive tourism. Knowledge of capture techniques and species usefulness is transmitted vertically in the community. The local ecological knowledge points to a population decline over time and attributes such decline to increased fishing. We hope the characterization provided in this study will contribute to the effective management of this species.
\end{abstract}

Keywords: Shell-Based Handicraft; Coastal Communities; Culture Transmission; King Helmet; Ethnoecology

\footnotetext{
1 Programa de Pós-Graduação em Ciências Biológicas (Zoologia), CCEN, Universidade Federal da Paraíba, João Pessoa, PB, 58059-970, Brasil.

2 Universidade Estadual da Paraíba, Departamento de Biologia, Campus I, Campina Grande, PB, 58429-500, Brasil.

* Corresponding author. $\triangle \mathrm{E}$-mail address: E.L.S.M (ellorilsmota@gmail.com)*, R.R.N.A. (romulo_nobrega@yahoo.com.br), T.L.P.D. (thelmalpdias@gmail.com)
}

\section{Significance Statement}

Cassis tuberosa is an important fishing resource throughout its distribution and its capture can affect the marine food chain. Here, we assess the fishing and trade of this species and what its economic importance is for coastal human communities in northeastern Brazil. Our method involved the direct participation of fishermen and users of this resource, allowing us to understand the socioeconomic relevance of fishing for this gastropod locally. In addition, our study can guide measures to control fishing and conservation of this species, helping to maintain the integrity of its wild populations. 


\section{INTRODUCTION}

Human populations have been using marine mollusks since prehistoric times, even before fishing began (Diegues 1983), for food, decoration, tools, folk medicine, and magico-religious rituals (Cross 1967; Wells 1981; Dias et al. 2011; Léo-Neto et al. 2012; Alves et al. 2018a). In modern times, some species are in high demand as marine curiosities and there is increased pressure on exploited species. It is estimated that at least 5,000 species of mollusk are marketed for ornamental purposes, mostly gastropods (Wood and Wells 1988). Due to their aesthetic value, there is an international trade in the shells of gastropods that has not yet been scientifically documented, and, most importantly, quantified. The governments of several nations as Australia, South Africa, Colombia, Bahamas, United States and others, are concerned about the overexploitation of these resources, and introduced their own laws to regulate the capture through the protection of marine molluscs (Wood 2001).

Among the species of major commercial interest are those belonging to large genera, such as Strombus spp. (Strombidae) and Cassis spp. (Cassidae) (Nieto-Bernal et al. 2013). The king helmet, Cassis tuberosa, is one of the most beautiful and exploited large gastropods on the Brazilian coast (Dias et al. 2017). This gastropod occurs in low densities in the Colombian Caribbean region; it is on the list of endangered Colombian species and considered vulnerable (Ardila et al. 2002). C. tuberosa is found from northern Carolina to Brazil (Rios 2009), including the Caribbean, Gulf of Mexico and the Cape Verde Islands (Tewfik and Scheuer 2013). In Brazil, it is distributed from Pará to Espírito Santo (Rios 2009; Dias et al. 2017). However, the conservation status of this species throughout its entire range is unknown, making it difficult to include it in global endangered species lists (e.g. the IUCN Red List of Threatened Species).

Nearly five decades ago C. tuberosa was considered one of the most abundant large gastropods in northeastern Brazil (Matthews and Coelho 1972); now it is included in the "near threatened" category by the Brazilian Ministry of Environment. The exploitation of C. tuberosa is facilitated by its inhabitation of shallow coastal environments, making it easily captured. According to Dias et al. (2011), shells of this species are usually sold in the marine ornamental trade in the northeast region of Brazil as one of the most common components of decorative and utilitarian handicrafts.

Despite increasing records in the scientific literature on the various uses $C$. tuberosa has to humans, there is no information on the quantity of this species being extracted by fishing activities. In general, the lack of monitoring of the trade in marine species makes it difficult to establish effective resource management strategies (Wood 2001). For the definition of sustainable management strategies, it is fundamental to identify and characterize the productive chains of marine resources (Nascimento et al. 2017), especially when a species is threatened. In this scenario, information from the people involved in the resource exploitation, together with scientific knowledge, is essential for planning and realizing conservation and management strategies. Ethnozoological studies have made important contributions to understanding the context of animal exploitation, its implications, and possible strategies to mitigate its impacts (Alves et al. 2018b). In situations where there is no data to provide a historical basis for the 
assessment of ecological systems, local ecological knowledge can help researchers piece together the history by recording the information passed along the generations on relationships between the inhabitants of traditional communities, the species, and its environment (Berkes et al. 2000).

By collating the knowledge of artisan fishermen, our study has provided a characterization of the catch and trade of $C$. tuberosa in coastal areas of northeastern Brazil, where there are no formal records of its exploitation. The information obtained achieves the objective of describing economic aspects of the capture of this marine gastropod, such as its trade chain, and how it participates in the local trade of fishing communities.

\section{MATERIAL AND METHODS}

\section{Study areas}

The research was carried out in six coastal communities in the State of Paraíba, northeast Brazil, located in the municipalities of Rio Tinto, Lucena, Cabedelo, Conde, and Pitimbu (Figure 1). In all selected areas, there were previous records of the occurrence of Cassis tuberosa, as well as information on its intensive capture and commercialization.

The community of Barra de Mamanguape (646'42.23"S; $\left.34^{\circ} 55^{\prime} 22.91 " \mathrm{~W}\right)$, located in the municipality of Rio Tinto on the north coast of the state, is located within the limits of the Barra do Rio Mamanguape Environmental Protection Area (a federal marine protected area). The main fishing resources used by the community are fish, seafood and lobsters that are caught in the surrounding area and in the estuary of the Mamanguape River (Mourão and Nordi 2003). The gastropod C. tuberosa is commonly caught in the beach area and on the sandstone reefs located at the mouth of the Mamanguape River.

Lucena is a municipality located to the north of the Paraíba River estuary (653'53.50"S; $\left.34^{\circ} 52^{\prime} 18.35^{\prime \prime W}\right)$. The studied fishing community mainly focuses on beach trawling, in which resources, such as fish and crustaceans, and especially shrimp, are obtained. The resources are sold in the region itself, sent to other cities, ordered by bars and restaurants, or are consumed by the fishermen themselves and their families. In the community, there is a shell trade for ornamental purposes, C. tuberosa is among the species sold.

The beach community of Formosa (6 $6^{\circ} 57^{\prime} 59.48 " \mathrm{~S}$; $\left.34^{\circ} 49^{\prime} 59.70^{\prime \prime} \mathrm{O}\right)$ is located at the northern end of the city of Cabedelo, along the central coast of the state. Artisan fishing is quite common in the area, and the fishery resources are mainly obtained from reef areas located parallel to the coastline, about $1 \mathrm{~km}$ away from the beach. The fish is sold in bars and restaurants on the beaches of the community or used for own consumption. Large shells are captured and sold at craft stores in Cabedelo city.

The community of Jacumã beach ( $7^{\circ} 17^{\prime} 18.43^{\prime \prime S}$; $\left.34^{\circ} 48^{\prime} 8.93^{\prime \prime W}\right)$ is located on the southern coast of the state and belongs to the municipality of Conde. Fishing is a large part of the community's economy, and the fish trade is mainly for local consumption. The beach is a strong tourist destination and has the presence of several craft stores that sell shells that are caught by the fishermen of the community even though in adjacent areas.

The community of Pitimbu $\left(7^{\circ} 28^{\prime} 27.40 " S\right.$; $\left.34^{\circ} 48^{\prime} 24.96 " \mathrm{~W}\right)$, also located on the southern coast of Paraíba, undertakes fishing activities in shallow reefs that are about $1 \mathrm{~km}$ from the coastline. Fishing 
through diving is more common, with the main targets being fish, octopus, and lobster. Lobster offshore fishing is also widely practiced in periods permitted under Brazilian law. Fishing is basically to supply the local commerce, which in turn, develops due to the very frequent tourism in the region. During the largest amount of tourist visitation, it is common the shell trade of $C$. tuberosa and the consume their meat in bars and restaurants in the community.

The community of Acaú $\left(7^{\circ} 32^{\prime} 37.04 " S\right.$; $\left.34^{\circ} 49^{\prime} 30.94 " \mathrm{~W}\right)$ is within the limits of the
Acaú-Goiana Extractive Reserve, located in the extreme south of the state, in the municipality of Pitimbu, on the border with the state of Pernambuco. The most common fishing activity is lobster fishing and artisanal trawling. Fish supplies local trade and is sold on a large scale to other regions of the Northeast. The catching of shells of $C$. tuberosa and other large gastropods such as Lobatus goliath is mainly made during the lobster offshore fishing.

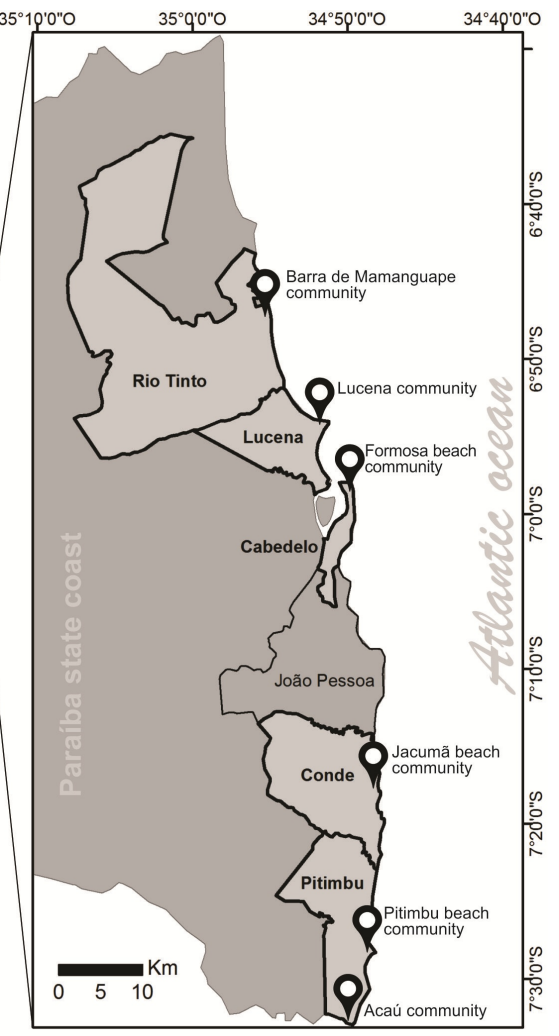

Figure 1. Map of the coast of Paraíba state, Northeastern Brazil, and indication of studied communities.

\section{Data collection}

To obtain the information, interviews were conducted with local fishermen through semi-structured questionnaires (Huntington 2000) and informal conversations. Were performed 61 interviews, being 10 in Barra de Mamanguape, 10 in Lucena, 10 in
Formosa, 8 in Jacumã, 13 in Pitimbu e 10 in Acaú. The questionnaires included information on aspects of the fishing activity undertaken by the respondent and specific questions about catch, trade, and local ecological knowledge of the Cassis tuberosa gastropod, such as frequency and purpose of catch, type of trade, uses of the shell, 
habitat characterization, and species' diet.

Among the main questions in the questionnaire, we highlight: "What do you fish?"; "Do you fish day or night?"; "What tool do you use to fish?"; "How many times do you go out fish per month?"; "Do you see this shell a lot? Do you think there is more today than before?"; "Have you ever captured this shell? How long does? Why did you get it?"; "How does this animal live? Where can I find?"; "What does this animal eat?"; "Have you eaten the meat of this animal?"; "Do you know who can sell me a shell? How much?"; "What do people buy this shell for?".

By answering these questions, fishermen help us to understand aspects of the fishing activities of the communities, the participation of the gastropod as a fishing resource, data on prices and purposes of capturing and shell trade, in addition to indicating the level of knowledge of the fishermen about the ecology of the species.

The sample of respondents was obtained through the technique called "snowball", in which fishermen initially interviewed other locals that captured C. tuberosa. Participant observations were made of the non-member type (Stebbins 1987), to confirm information given in the interviews and to provide complementary ethnographic data. Before each interview, the nature and objectives of the work were explained, and the consent of the interviewee was obtained through the Informed Consent Form. This study was approved by the Ethics Committee of the Federal University of Paraíba (CAAE 05757512.5.0000.5208).

\section{Data analysis}

Responses to binary questions (as for example: "day" or "night" fishing period; have you ever caught this conch? "Yes or no"; have you ever eaten the meat of this conch? "Yes or no") were treated as categorical data. Open-ended questions (with qualitative responses) were categorized according to the main themes. For example, when asked about the justification for claiming that the species population is declining, the answer "because there is more fisherman today than before" was categorized as "catch intensification". Open-ended questions with a numerical answer (for example, those related to age, household size, and fishing income) were treated as numerical data. The categorized responses were quantified and presented as numerical percentages. T-tests were carried out to determine if the fishermen's perception of the population decline of the species differed with age and fishing experience. Age and fishing experience (in years) were normally distributed (Lilliefors normality test: age, $p=n s$, experience, $p=n s$ ).

\section{RESULTS}

The results concerning mainly the characterization of fishing activities, and additional information about the fishermen (such as age and time of experience) were organized in the table1.

The fishermen carried out their fishing activities during both day and night periods (50.8\%), with more than 10 fishing activities per month $(83.6 \%)$. Of these, $46.7 \%$ left for more than 20 days per month to fish. The tools used by most fishermen were trawl net, tarrafa net, hold net, and hook and line. Fishing by diving was used by $26.7 \%$ of the fishermen interviewed, and they used tools ("visga" and "bicheiro") suitable for catching octopus, lobsters, and other crustaceans.

All interviewees said they knew the gastropod, and a large percentage $(70.5 \%)$ stated that they often observed C. tuberosa 
Table 1. Representativity data about the fishing activities and others informations.

\begin{tabular}{|c|c|c|c|}
\hline & Mean & SD & \\
\hline Age (years) & 47.1 & 12.3 & $\begin{array}{l}22-76 \\
\text { years }\end{array}$ \\
\hline Fishing experience (years) & 32.6 & 13.3 & $\begin{array}{l}12-66 \\
\text { years }\end{array}$ \\
\hline \multirow{3}{*}{ Lives in the comunity for over 30 years } & $\%$ & $\mathbf{N}$ & \\
\hline & 70 & 43 & \\
\hline & & $\%$ & $\mathbf{N}$ \\
\hline \multirow[t]{2}{*}{ Income sources } & Fishing & 80.3 & 49 \\
\hline & Others & 19.7 & 12 \\
\hline \multirow[t]{3}{*}{ Main fishing resource } & Fish & 49.2 & 30 \\
\hline & Crustacean & 32.7 & 20 \\
\hline & Mollusks & 18.1 & 11 \\
\hline \multirow[t]{3}{*}{ Cassis tuberosa capture period } & Day & 63.9 & 39 \\
\hline & Night & 8.2 & 5 \\
\hline & Both & 27.9 & 17 \\
\hline
\end{tabular}

in the wild. Seven popular names were attributed to the species according to the interviewees: "conch", "purple conch", "cracked conch", "common conch", "ironwork conch", "tooth shell", and "snail". The nomenclatures refer to the characteristics of morphology, coloration, and ornamentation of the shell.

When asked about a possible decline in the king helmet over time (about 5 years ago), $54.1 \%$ of the fishermen recognized that there was an apparent population decline in the gastropod over the last 5 years. When asked the reason, the decline was attributed to increased catch, and this was linked to the increase in the number of fishermen over the years. Although most of the informants pointed to a decrease in the abundance of specimens in the wild, this perception did not differ for age $(\mathrm{t}=0.16$, $p=0.8)$ or fishing experience $(t=0.41$, $p=0.67$ ).
Live specimens of $C$. tuberosa in the wild had already been captured by $93.4 \%$ of the interviewees. When asked about when the last king helmet was caught, most said it was days or weeks ago (51.7\%). $17.2 \%$ of the fishermen interviewed captured specimens months ago. This suggests a moderate to high frequency removal of specimens from their habitats. The informants reported that when they found gastropods, they always captured all the specimens they were able to carry.

According to $63.9 \%$ of fishermen ( $\mathrm{N}=39$ ), C. tuberosa was caught preferentially during the day, although, $8.2 \%$ preferred catching it at night, and $26.2 \%$ during both periods. Informants who preferred the daytime period claimed that daylight facilitates the search for the gastropod, as it may be buried in the sand. The informants who preferred the nocturnal period stated that without the heat 
of the day, the species does not bury itself and freely moves on the sand surface.

According to the interviewees, the capture of the king helmet is influenced by five motivations: "to sell the shell" $(\mathrm{N}=11)$, "to eat" $(\mathrm{N}=11)$, "to gift" $(\mathrm{N}=7)$, "beauty" $(\mathrm{N}=18)$, and "for personal collection" $(\mathrm{N}=14)$. We observed that economic gain is not the main motivation for capturing this species.

Using the gastropod as a food resource seemed to be common throughout the studied communities, as the practice was recorded in all localities. In general, $62.3 \%$ of the informants had used meat from the gastropod as food. Regarding the use of the shell, all the interviewees said they currently, or had previously, possessed the shell in their homes as a decorative object. During visits, the presence of the gastropod shell was recorded in the residences of $23 \%$ of the interviewees (Figure 2).

The respondents were asked if they knew that others commercialized the shell or meat of the king helmet, and $73.8 \%$ of the interviewees knew other fishermen who sold products of the species in their community. This suggests that the chain of capture and trade of the gastropod begins within the communities themselves, characterizing an internal market. It was observed that for the trade of $C$. tuberosa in the studied areas, there was no necessity for middlemen. The fishermen themselves captured the specimens and sold the products to local decorative and handicraft fairs, bars, and restaurants.

From the report of 14 informants, it was possible to follow the complete process from the capture to the sale of the gastropod meat and shells direct to the final consumer (e.g. tourists, local bathers). The fishermen's reports indicated that commercialization of C. tuberosa products (especially meat and shells) occurs more intensively in the summer, the period of greatest tourist visitation in the region (Figure 3 ).

When questioned if all the shells found would be for sale, $78.7 \%$ of respondents stated that all shells could be sold, including those encrusted with organisms. According to the informants, the shells were prepared for sale by removal of epibiotic organisms (e.g., macroalgae, bryozoans, and barnacles). After cleaning, the shells were used as "decoration" (53 citations), "crafts" (29 citations), and "sound instruments" (6 citations). Other types of use have been cited as "gift", "to listen to sound of the sea" and "magic". The use as "sound instrument"'

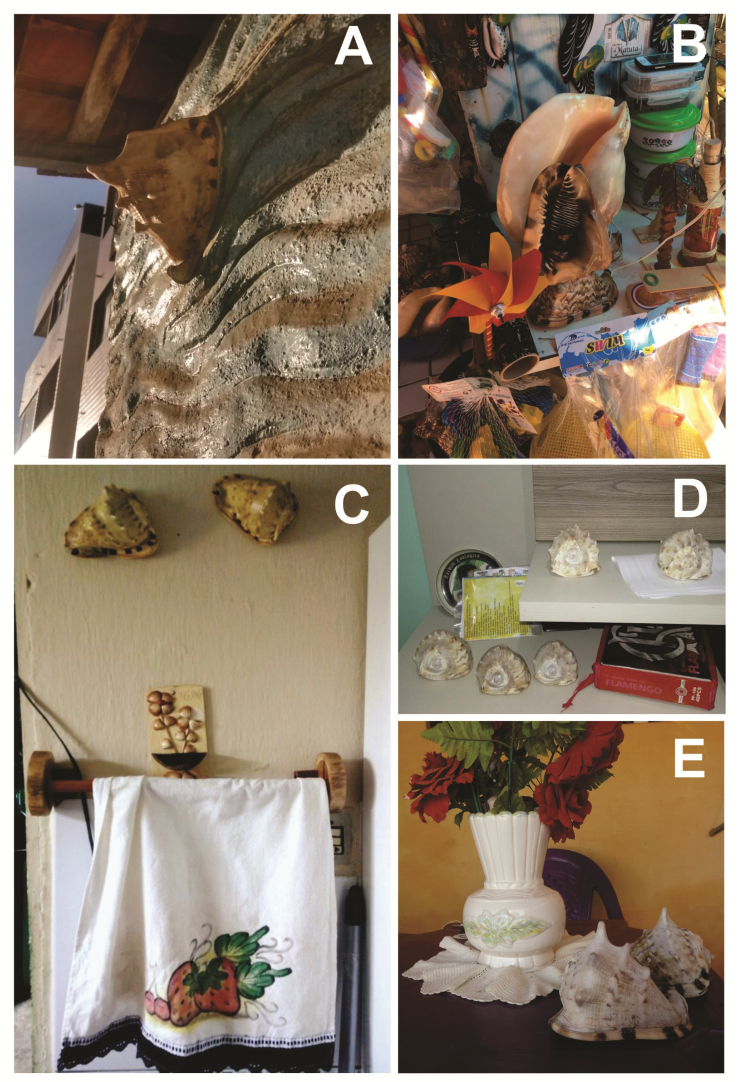

Figure 2. Uses of Cassis tuberosa shell for ornamental purposes in homes and stores in the studied communities. (A) Shell used as decoration in the fish market in the Pitimbu community. (B) Shell-based products in the handicraft store of Pitimbu community. (C-E) Shells of $C$. tuberosa used as ornament for home decoration. Photo: Ellori Mota. 


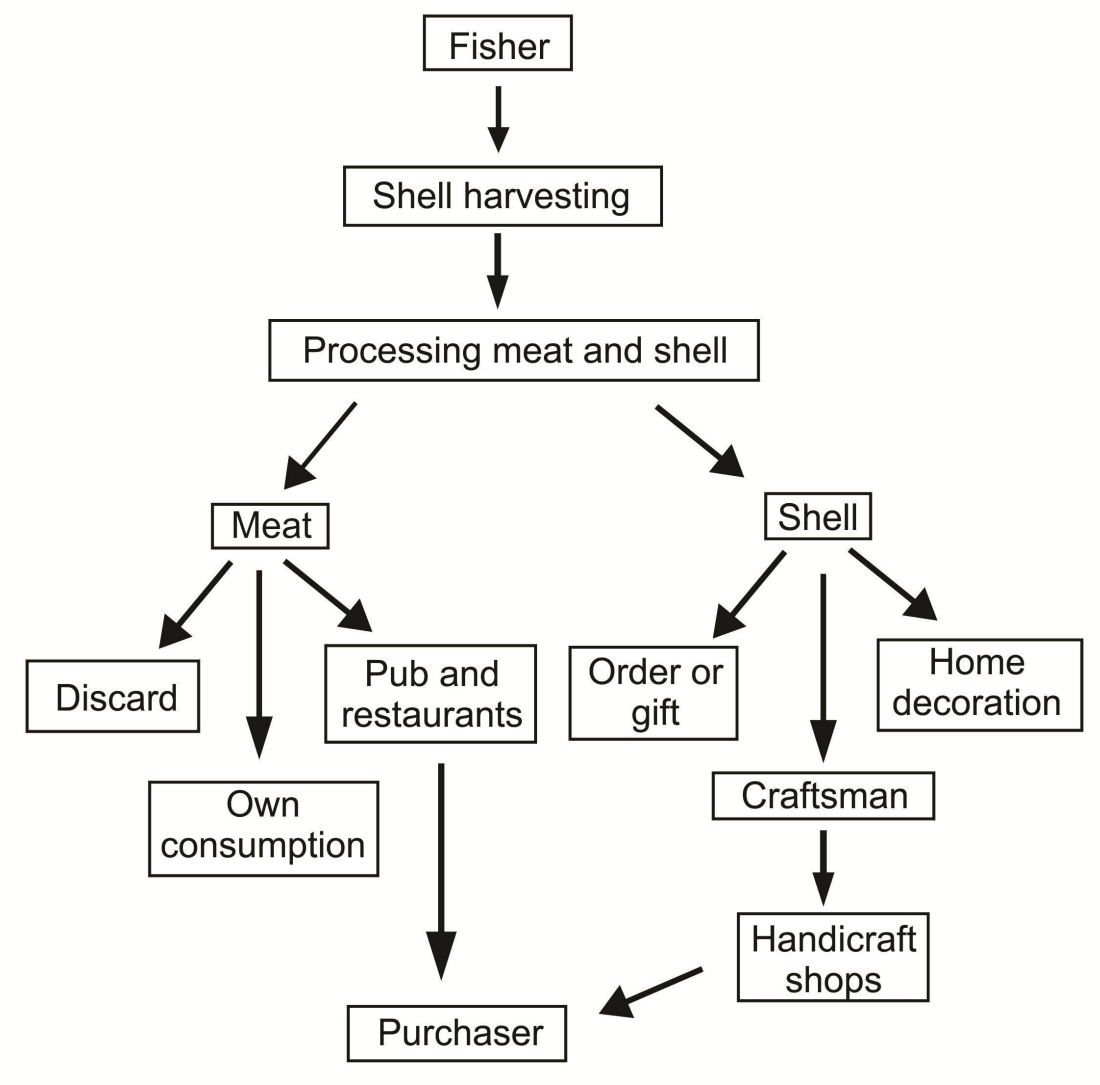

Figure 3. Production chain of the meet and shells of Cassis tuberosa in selected communities along the coast of Paraíba state, NE Brazil.

refers to the use of the shell as an instrument to produce a loud sound like a whistle. According to the informants, these were used for decades by the crew aboard vessels seeking to warn the population on the shore about their arrival.

The sale price of the king helmet shells varied by size, ranging from US $\$ 1.50$ to US $\$ 30.00$. Respondents reported that a few years ago, the shell price was US\$35.00, but currently the value is exceptionally low. In general, prices quoted were between US $\$ 0.70$ and US $\$ 1.60 \quad(56.25 \%$ of informants indicated this price range) and were attributed to the sale of the shell alone. The highest prices quoted, between US $\$ 15.00$ and US $\$ 30.00$, were attributed to craft pieces that used the shell of $C$. tuberosa for decoration.

According to the informants' description, C. tuberosa is caught in three ways: (1) through free diving while fishing for octopus and lobster, eventually using tools (visga and bicheiro) to search for specimens buried in the sand; (2) as a by-catch in bottom trawls, either in shallow or deep coastal areas; or (3) during random searches on the beach or intertidal sandy banks, during low tide.

Regarding the use of the gastropod meat, fishermen reported four ways of separating the soft part of the shell: (1) by repeatedly tapping the gastropod against the sand on the beach until the soft part of the animal detaches from the shell; (2) by placing the gastropod in a pan of boiling water until the soft part loosens from the shell; (3) by 
attaching a metal hook to the muscular foot of the gastropod and hanging on a clothesline so that, through gravity, the heavier shell detaches from the soft part and falls to the ground; and (4) by keeping the gastropod in a container with ice, where it is anesthetized by the low temperature, and using force and tools such as a metal hook to pull and detach the soft part of the shell. Fishermen often bury the shells of gastropods for a various period, so that an internal cleaning process can take place through decomposition by detritivore organisms present in the soil.

All fishermen described characteristics of the habitat where $C$. tuberosa can be found. The most cited environments of rock and sand, and the habit of burying in the sandy substrate was frequently mentioned. Regarding the diet of the gastropod, 16 informants did not know how to respond. The other respondents $(\mathrm{N}=45)$ indicated seven food items: sand dollars and sea urchins (11 citations), algae (21 citations), sand (12 citations), shellfish (2 citations), crustaceans (3 citations), and fish (2 citations). A single interviewee answered that the animal feeds by filtering the sea water.

When asked about predators of the gastropod, 28 fishermen could not answer, 24 indicated the octopus, and seven indicated turtles. Fish, man, and shark were cited three times, while dolphin and crab were cited twice. Three of the informants believed that there are no predators for $C$. tuberosa.

A total of nine fishery follow-ups were conducted with informants from four of the six communities studied. Three activities were followed in the community of Barra de Mamanguape, two in the community of Lucena, three in the community of Praia Formosa, and one in the community of Pitimbu.

During the fishing activities, it was observed that $C$. tuberosa was not the main target of the catch: fisheries mainly focused on fish, lobsters, and octopuses. This aspect reveals that the king helmet is not the main interest of the fishermen, only being caught occasionally if found during fishing. It was also noticed that the informants knew how to indicate places the gastropod frequently occurred, and the gastropod was sighted in eight of the nine fisheries monitored. The fishermen explained that the species is usually found close to rocks and is buried in the sand most of the time. They also reported that it is difficult to see specimens in the wild due to their burying habit.

In one of the fishing groups we accompanied, we recorded the technique of removing the meat from the shell by successive pitching of the mollusk against the sand of the beach (Figure 4A). The fisheries were commonly accompanied by the children of the fishermen, who assisted the parents with the boat and fishing by diving. Just like the parents, the children used specific tools to catch octopus and lobster. In one of the recorded fisheries, a 12-year-old child removed the meat from the gastropod using the technique described (Figure 4C, D).

Some additional information was obtained through informal conversations with the interviewees, including historical aspects of C. tuberosa. For example, it has been found that the practice of using king helmet meat as food by local communities is old, but there has been a greater incidence of the practice recently. Information from the interviewees reinforces: "in the past, some restaurants bought the meat", "about 10 years ago they started eating more", "when they learned that other people ate and liked it, they started to get more". A worrisome aspect of the capture of meat for consumption is the number of specimens 

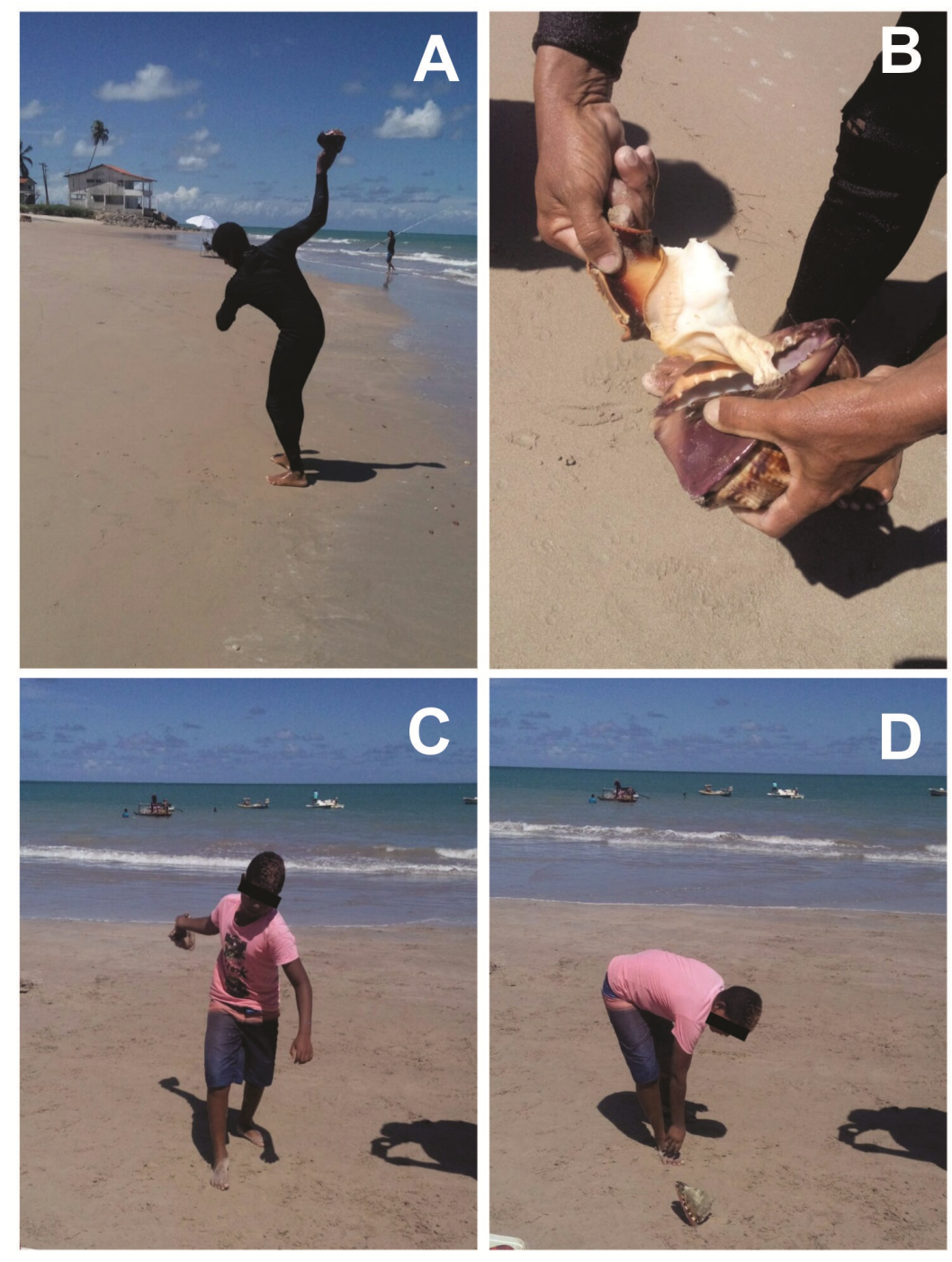

Figure 4. Fishermen developing technique of removal of the meat of an individual of Cassis tuberosa captured in the Pitimbu beach. (A) Fisherman shooting the gastropod against the sand on the beach. (B) Fisherman detaching meat from shell. (C-D) Child developing the technique. Photo: Ellori Mota. needed to compose a meal: "for a good stew, you have to get about 10 conchs". The catch of the king helmet is commonly related to lobster fishing. Informants reported that while catching lobster, catching C. tuberosa was facilitated and frequent: "when lobster fishing is permitted, it is easier to get the conch". Another form of capture of the gastropod is through sea-bottom trawling, in which many individuals are accidentally caught.

In relation to the sale of the shell, it was possible to observe an increase in value along the chain of commercialization when the shell was sold for ornamental purposes. Informants $(\mathrm{N}=5)$ reported that "the fishermen sell the shell to the artisan for a low price, about US $\$ 0.25$, and the craft stores sell (lamps) for up to US\$25.00 to tourists". The popular belief that having a shell of the king helmet at home is a sign of bad luck was reported twice. Twice, the use of shells was indicated to be for magicoreligious purposes, as a fundamental piece for sympathies and religious cults.

Informants recognized the population decline of the species and admitted that fishing is one of the causes. It was also 
evidenced that they were aware that the capture of the species is illegal: "if the IBAMA (Brazilian Institute of Environment and Renewable Natural Resources) finds someone catching or selling the conch shell, they will be arrested".

\section{DISCUSSION}

The capture and trade of Cassis tuberosa occurs entirely in traditional communities of fishermen, who are the direct collectors and sellers of specimens. In the chain of trade of gastropods, there is no function for the middleman between fisherman and export companies, as observed by Salim et al. (2017) in India. This differs from the commercial chain of some bivalve species in the northeast of Brazil (Nishida et al. 2006), which relies strongly on intermediaries to reach the markets and promote sales (Rocha and Pinkerton 2015). It is known that the work of intermediaries can make the chain of commerce more complex and, therefore, hamper the protection policies of these species (Nijman et al. 2015). In addition, middlemen make the product more expensive and increase the discrepancy between the profit of the collector and the final seller.

Our results present evidence of the importance of the species as a part of the resources used by fishing communities, either for consumption and own use or to supplement family income. The significant economic potential of selling shellfish for ornamental purposes (Dias et al. 2011) means the ornamental trade in shells can become larger in scale (Nijman et al. 2015). However, very few studies have identified and characterized the commercial chains for marine mollusks sold in the ornamental shell trade (Nijman et al. 2016; Salim et al. 2017). In addition, little attention has been given to the livelihood of fishing communities involved in the shell trade (Simard et al. 2018).

The beauty the shell of the king helmet is the main reason the species is captured. C. tuberosa is one of the main target species in the trade of marine curiosities, due to the large size and beauty of the shell at all growth stages (Dias et al. 2011; Dias et al. 2017). Their capture is further facilitated by the distribution of the species in shallow regions (Rios 2009), making it easily accessible to locals and visitors.

Among the uses for $C$. tuberosa we identified throughout the study, its use for decorative purposes was most common. The capture of $C$. tuberosa is driven by the beauty, size, and frequency the wild specimens are encountered, and they are not the main target of fishing in the studied communities. Therefore, the exploitation of this species can be considered a cultural activity. In several regions of the world, gastropod species are bought or collected as "portable memories" by people who frequent the coastal areas where such species occur (Gibbons and Remaneva 2011; Gössling et al. 2004). The collection of helmets as part of a cultural tradition or habit may also contribute to the significant reduction in its population (Newton et al. 1993).

On the other hand, from a conservation perspective, the fact that fishing communities have a cultural practice of $C$. tuberosa use can facilitate management strategies. Since the resource is not a significant source of income with a major role in the livelihood of families, the socioeconomic impact of a catch limitation or prohibition is less. However, like other tropical species with attractive shell ornamentation, C. tuberosa is a part of the thriving ornamental trade existing within the communities. In addition, the catch is 
enhanced by tourism in these areas. The development of tourism has increased the market for souvenirs with consequent pressures on marine resources (Nijman and Lee 2016; Dias et al. 2011; Gössling et al. 2004). In the case of the king helmet, the buyer can obtain the whole shell as a decorative piece or the shell may be incorporated into pieces of handicraft, together with other species (Alves et al. 2018a).

In this scenario, the role of environmental protection agencies in controlling these resources becomes paramount, since the removal of key species from nature brings with it ecological consequences that will easily reflect on the landscape of coastal ecosystems and tourist activities. An example of this is the fact that $C$. tuberosa is a predator of sea urchins in reef ecosystems (see review by Dias et al. 2017), where tourism is intense. The removal of this predator may lead to an overpopulation of sea urchins, which will affect the visitation of certain places by tourists, either due to the risk of accidents or the bioerosion caused by sea urchins.

The use of the mollusk as food was also recorded in all the studied communities. Until this study, this usage was recorded only for other Cassidae in the Caribbean region (Abbott 1968; Cross 1967). This study revealed the use of $C$. tuberosa as a food resource for traditional populations on the Brazilian coast. Catching the gastropod for consumption is common among fishermen, but it does not occur commercially due to the occasional capture of the species. Despite this, the practice is worrisome, as there is the risk of an increasing demand for meat from the gastropod for commercial purposes. If this occurs, these incidental catches may soon be directed towards the collapse of other fisheries resources. In addition, the artisanal capture of the king helmet, can have a strong negative impact on the natural populations.

The capture of the king helmet is associated with lobster fishing, so it is necessary to monitor this fishery. The exploitation of the lobster has reached high levels in several areas of the Brazilian coast, leading to the overexploitation of this resource (Andrade 2015). Thus, populations of C. tuberosa may also suffer from overexploitation due to the indiscriminate removal of specimens during the lobster fishing.

Bycatch or incidental capture of $C$. tuberosa through trawling, the target of which is fish and shrimp rather than the gastropod, was a form of catch commonly mentioned by the fishermen. The impact of bycatch on populations of large gastropods is still poorly understood (e.g. Carranza and Horta 2008). The records are also scant for species of the family Cassidae (Gibinkumar et al. 2012). The information on bycatch provided by the fishermen in the present study are the earliest records for the king helmet, despite occasional catches. These records reveal new aspects of the capture of the species that require study, such as the quantification of bycatch and, consequently, the impact of these events on the populations during their occurrence.

The most coveted specimens in the decorative trade are those with the largest shell size, which results in the frequent removal of sexually mature individuals from the reef environment. An individual of $C$. tuberosa, with a $19 \mathrm{~cm}$ long shell, was recorded spawning on macroalgae fronds (Dias and Mota 2015), suggesting, for the first time, a relationship between the size of the shell and the stage of species maturation. This spawning, recorded in loco, also showed the importance of the 
macroalgae banks as spawning grounds for this species. In addition, depletion of mature individuals in the wild may result in rapid local extinction due to the "Allee Effect", in which gamete densities become too low to produce positive recruitment values (Stoner and Ray-Culp 2000).

The fishermen described an almost weekly frequency of capture of $C$. tuberosa from the environment. Still, they do not recognize predators of the species, suggesting they may not be aware of the impacts caused by the gastropod's removal from nature. From the perception of the fishermen, it is possible to characterize the relationships between man and animal, which guides practical objectives for the creation of policies and actions for the conservation of the species, along with community well-being. Based on this information, we emphasize the importance of ethnobiological studies, since the perception of the local community provides important information on the observations, understanding, and interpretations of the socio-ecological relations of the community (Bennett 2016). In this way, measures taken by the environmental agencies can be based on popular knowledge and the species uses by fishermen.

The fishermen have perceived a population decline in the species over time and attribute such disappearance to the increasing catch rate. This perception, facilitated by the close relationship between the community and the environment, is often the only source of information for historical changes in local marine stocks (Huntington 2000), and should be used when long-term population data are unavailable.

The observation of children accompanying fisheries and reproducing predatory behavior on $C$. tuberosa, characterizes the renewal of exploitation cycles and the cultural transmission of the activity. Cultural transmission in the infantile stage is mainly vertical in form, with the parents being the first to transmit knowledge about the techniques (Hewlett et al. 2011). Therefore, actions in conservation and management of the species should consider this aspect, and conduct educational programs within traditional communities, especially in schools.

\section{CONCLUSIONS}

In conclusion, we have gathered, for the first time, several important aspects of the catch and trade chain of the marine gastropod C. tuberosa, which highlight the role of traditional ecological knowledge of six fishing communities on the northeast coast of Brazil. This study showed that C. tuberosa is of relative importance to fishermen and is not a primary resource for the income of the population. The information presented here can contribute to the development of conservation and management actions for $C$. tuberosa by environmental agencies and authorities responsible for fishery resource management.

Although the capture of the species occurs occasionally (non-commercial) and is not the main purpose of fishing, the increased interest in this gastropod, or even the increase of family groups exercising the capture on this species even for their own consumption, may generate a local scale overexploitation scheme with higher scaling impacts.

We recommend that any conservation action aimed at protecting this species includes community educational activities aimed at the fishermen and their children, which should prioritize information about the ecological role of the species in the wild and how it affects fishing and tourism activities. 
Tourists should also be advised to avoid buying souvenirs involving large mollusk species. Reproduction biology, medium-term population trends, and the impacts of removing this species from the wild are unknown throughout its distribution. Therefore, we urgently need to promote the protection of this species, for the benefit of the populations and their ecosystems.

\section{ACKNOWLEDGEMENTS}

We thank Jessica Lima, Heliene Mota and Rafaela Duarte for their help with the fieldwork. Thanks to the key informants Arlindo, Romildo, Luís and Josivan, and all fishermen whose knowledge contributed to this research. CAPES (Coordenação de Aperfeiçoamento de Pessoal de Nível Superior) supported this research through a scholarship to ELS Mota. Essential financial support was provided by PADI Foundation (Grant \# 8069) and Conchologists of America (2013 Grants to Malacology). RRN Alves was supported by $\mathrm{CNPq}$ (Conselho Nacional de Desenvolvimento Científico e Tecnológico) grant productivity research fellowship. Paraíba State University (Marine Biology Laboratory) and Programa de PósGraduação em Ecologia e Conservação (PPGEC/UEPB) provided essential logistical support.

\section{DATA AVAILABILITY}

The data used to support the findings of this study are available from the corresponding author upon reasonable request.

\section{CONFLICTS OF INTEREST}

The authors have no conflicts of interest to declare.

\section{CONTRIBUTION STATEMENT}

Conceived the present idea: ELSM and TLPD

Carried out the field work: ELSM

Carried out the data analysis: ELSM

Wrote the first draft of the manuscript:

ELSM and TLPD

Review and final draft the manuscript:

ELSM, TLPD and RRNA

Supervision: TLPD and RRNA

\section{REFERENCES}

Abbott RT (1968) Helmet shells of the world (Cassidae): part 1. In: Abbott RT (ed) IndoPacific. Mollusca. 2 edn. The department of Mollusks - Academy of Natural Sciences of Philadelphia, pp. 7-201

Alves RRN, Mota ELS, Dias TLP (2018a) Use and commercialization of animals as decoration. In: Alves RRN, Albuquerque UP (eds) Ethnozoology: Animals in Our Lives. 1 edn. Academic Press - Elsevier, London, pp. 261-275

Alves RRN, Silva JS, Chaves LS, Albuquerque UP (2018b) Ethnozoology and Animal Conservation. In: Alves RRN, Albuquerque UP (eds) Ethnozoology: Animals in Our Lives. 1 edn. Academic Press - Elsevier, London, pp. 481-496

Andrade HA (2015) Stock assessment of the red spiny lobster (Panulirus argus) caught in the tropical southwestern Atlantic. Latin American Journal of Aquatic Research doi: 10.3856/vol43-issue1-fulltext-17

Ardila N, Navas GR, Reyes J (2002) Libro rojo de invertebrados marinos de Colombia. INVEMAR. Ministerio de Medio Ambiente. La serie Libros rojos de espécies amenazadas de Colombia, Bogotá, Colombia.

Bennett NJ (2016) Using perceptions as evidence to improve conservation and environmental management. Conservation biology doi: 10.1111/cobi.12681

Berkes F, Colding J, Folke C (2000) Rediscovery of traditional ecological knowledge as adaptive management. Ecological applications doi: 10.2307/2641280

Carranza A, Horta S (2008) Megabenthic 
gastropods in the outer Uruguayan continental shelf: composition, distribution and some effects of trawling. Revista de Biología Marina y Oceanografía doi: 10.4067/S0718-19572008000100014

Cross ER (1967) Helmet Shell Chowder. Hawaiian Shell News 15 (5): 7.

Dias TL, Leo-Neto NA, Alves RRN (2011) Molluscs in the marine curio and souvenir trade in NE Brazil: species composition and implications for their conservation and management. Biodiversity and Conservation doi: 10.1007/s10531-011-9991-5

Dias TLP, Mota ELS (2015) First record of Cassis tuberosa spawning in the wild (northeast Brazil). Marine Biodiversity Records doi: 10.1017/S1755267215001050

Dias TLP, Mota ELS, Duarte RCS, Alves RRN (2017) What do we know about Cassis tuberosa (Mollusca: Cassidae), a heavily exploited marine gastropod? Ethnobiology and Conservation doi: 10.15451/ec2017086.16113

Diegues AC (1983) Pescadores, camponeses e trabalhadores do mar. São Paulo: Ática.

Gibbons E, Remaneva L (2011) Curio trade: Southwest Madagascar. London: Reef Doctor.

Gibinkumar TR, Sabu S, Pravin P, Boopendranath MR (2012) Bycatch characterization of shrimp trawl landings off southwest coast of India. Fishery Technology 49: 132-140.

Gössling S, Kunkel T, Schumacher K, Zilger M (2004) Use of molluscs, fish, and other marine taxa by tourism in Zanzibar, Tanzania. Biodiversity and Conservation doi: 10.1007/s10531-004-2139-0

Hewlett BS, Fouts HN, Boyette AH, Hewlett BL (2011) Social learning among Congo Basin hunter-gatherers. Philosophical Transactions of the Royal Society doi: 10.1098/rstb.2010.0373

Huntington HP (2000) Using traditional ecological knowledge in science: methods and applications. Ecological Applications doi: $10.2307 / 2641282$

Leo-Neto NA, Voeks RA, Dias TLP, Alves RRN (2012) Mollusks of Candomblé: symbolic and ritualistic importance. Journal of Ethnobiology and Ethnomedicine doi: 10.1186/1746-4269-8-10

Matthews HR, Coelho ACS (1972) Superfamília Tonnaceae do Brasil. IV - Família Cassidae
(Mollusca, Gastropoda). Arquivos de Ciências do Mar 12 (1): 1-16.

Mourão JS, Nordi N (2003) Etnoictiologia de pescadores artesanais do estuário do Rio Mamanguape, Paraíba, Brasil. Boletim do Instituto de Pesca 29 (1): 9 - 17.

Nascimento DM, Alves RRN, Barboza RRD, Schmidt AJ, Diele K, Mourão JS (2017) Commercial relationships between intermediaries and harvesters of the mangrove crab Ucides cordatus (Linnaeus, 1763) in the Mamanguape River estuary, Brazil, and their socio-ecological implications. Ecological Economics doi: 10.1016/j.ecolecon.2016.08.017

Newton LC, Parkes EVH, Thompson RC (1993) The effects of shell collecting on the abundance of gastropods on Tanzanian shores. Biological Conservation doi: 10.1016/0006-3207(93)90719-H

Nieto-Bernal R, Chasqui LV, Rodríguez AMR, Castro EG, Gil-Agudelo GL (2013) Composición, abundancia y distribuición de las poblaciones de gasterópodos de importancia comercial em La Guajira, Caribe colombiano. Revista de Biologia Tropical doi: 10.15517/RBT.V61I2.11168

Nijman V, Spaan D, Nekaris KA-I (2015) Largescale trade in legally protected marine mollusk shells from Java and Bali, Indonesia. PLoS ONE doi: 10.1371/journal.pone.0140593

Nijman V, Lee PB (2016) Trade in nautilus and other large marine molluscs as ornaments and decorations in Bali, Indonesia. Raffles Bulletin of Zoology 64: 368-373.

Nijman V, Spaan D, Sigaud M, Nekaris KA-I (2016) Addressing the open illegal trade in large marine mollusk shells in Pangandaran, Indonesia. Journal of Indonesian Natural History 4 (1): 12-18.

Nishida AK, Nordi N, Alves RRN (2006) Mollusc gathering in Northeast Brazil: an ethnoecological approach. Human Ecology doi: 10.1007/s10745-005-9005-x

Rios EC (2009) Compendium of Brazilian Sea Shells. Rio Grande: FURG.

Rocha LM, Pinkerton E (2015) Co-management of clams in Brazil: a framework to advance comparison. Ecology and Society doi: 10.5751/ES-07095-200107

Salim SS, Jagadis I, Venkatesan V, Rahman MR, 
Nashad M (2017) Gastropod landing, utilization and trade in India: A case study from Kollam, India. Journal of the Marine Biological Association of India doi: 10.6024/jmbai.2017.59.1.1879-14

Simard NS, Militz TA, Kinch J, Southgate PC (2018) Artisanal, shell-based handicraft in Papua New Guinea: Challenges and opportunities for livelihoods development. Ambio doi: 10.1007/s13280-018-1078-z

Stebbins RA (1987) Fitting in: the researcher as learner and participant. Quality and Quantity doi: 10.1007/BF00221719

Stoner AW, Ray-Culp M (2000) Evidence for Allee effects in an over-harvested marine gastropod: density-dependent mating and egg production. Marine Ecology Progress Series doi: 10.3354/meps202297

Tewfik A, Scheuer B (2013) Ecology of the King
Helmet, Cassis tuberosa (L.), in South Caicos. Caribbean Naturalist 2: 1-10.

Wells SM (1981) International trade in ornamental corals and shells. Proceedings of the Fourth International Coral Reef Symposium 1: 323-330.

Wood EM (2001) Global Advances in Conservation and Management of Marine Ornamental Resources. Aquatic Science Conservation doi: 10.1023/A:1011391700880

Wood E, Wells S (1988) The marine curio trade: conservation issues. A report for the Marine Conservation Society, United Kingdom.
Received: 09 September 2019

Accepted: 03 June 2020

Published: 08 June 2020 